\title{
Association between Gc genotype and susceptibility to TB is dependent on vitamin D status
}

\author{
A.R. Martineau*, A.C.C.S. Leandro*, S.T. Anderson, S.M. Newton, K.A. Wilkinson, \\ M.P. Nicol, S.M. Pienaar, K.H. Skolimowska, M.A. Rocha, V.C. Rolla, M. Levin, \\ R.N. Davidson, S.A. Bremner, C.J. Griffiths, B.S. Eley, \\ M.G. Bonecini-Almeida and R.J. Wilkinson
}

ABSTRACT: Group-specific component (Gc) variants of vitamin D binding protein differ in their affinity for vitamin $D$ metabolites that modulate antimycobacterial immunity. We conducted studies to determine whether Gc genotype associates with susceptibility to tuberculosis (TB).

The following subjects were recruited into case-control studies: in the UK, 123 adult TB patients and 140 controls, all of Gujarati Asian ethnic origin; in Brazil, 130 adult TB patients and 78 controls; and in South Africa, 281 children with TB and 182 controls. Gc genotypes were determined and their frequency was compared between cases versus controls. Serum 25hydroxyvitamin $D(25(\mathrm{OH}) \mathrm{D})$ concentrations were obtained retrospectively for 139 Gujarati Asians, and case-control analysis was stratified by vitamin $D$ status. Interferon (IFN) $-\gamma$ release assays were also performed on 36 Gujarati Asian TB contacts.

The Gc2/2 genotype was strongly associated with susceptibility to active TB in Gujarati Asians, compared with Gc1/1 genotype (OR 2.81, 95\% Cl 1.19-6.66; $p=0.009$ ). This association was preserved if serum $25(\mathrm{OH}) \mathrm{D}$ was $<20 \mathrm{nmol} \cdot \mathrm{L}^{-1} \quad(p=0.01)$ but not if serum $25(\mathrm{OH}) \mathrm{D}$ was $\geqslant 20 \mathrm{nmol} \cdot \mathrm{L}^{-1}(p=0.36)$.

Carriage of the Gc2 allele was associated with increased PPD of tuberculin-stimulated IFN- $\gamma$ release in Gujarati Asian TB contacts $(p=0.02)$. No association between Gc genotype and susceptibility to TB was observed in other ethnic groups studied.

KEYWORDS: Gc genotype, 25-hydroxyvitamin D, tuberculosis, vitamin D binding protein

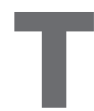

uberculosis (TB) is a leading global cause of death. Vitamin D deficiency associates with susceptibility to active $\mathrm{TB}$ in numerous settings [1] and vitamin D supplementation enhances antimycobacterial immunity [2]. Vitamin D is synthesised in the skin during exposure to ultraviolet (UV) light and is metabolised by the liver to form 25-hydroxyvitamin D $(25(\mathrm{OH}) \mathrm{D})$, the major circulating vitamin D metabolite and accepted measure of vitamin D status. $25(\mathrm{OH}) \mathrm{D}$ then undergoes a further hydroxylation step to form 1,25-dihydroxyvitamin D $\left(1,25(\mathrm{OH})_{2} \mathrm{D}\right)$, the immunomodulatory metabolite that enhances antimycobacterial activity by pleiotropic mechanisms, including the induction of antimicrobial peptides with antituberculous activity $[3,4]$ and the suppression of matrix metalloproteinase enzymes implicated in the degradation of pulmonary extracellular matrix [5].

Vitamin D metabolites in the circulation are bound to vitamin D binding protein (DBP), a highly expressed multifunctional 58-kDa serum glycoprotein encoded on chromosome 4 . The DBP locus is among the most polymorphic known [6]. Two common polymorphisms at codons $416($ GAT $\rightarrow$ GAG, Asp $\rightarrow$ Glu) and 420 (ACG $\rightarrow$ AAG, Thr $\rightarrow$ Lys) of exon 11 of the DBP gene (defined by the presence of restriction endonuclease sites for HaeIII and StyI, respectively) give rise to the three major electrophoretic variants of DBP, termed group-specific component 1 fast (Gc1F), Gc1 slow (Gc1S) and Gc2. These variants differ in their functional characteristics: the Gc1F and Gc1S variants have been reported to have greater affinity for $25(\mathrm{OH}) \mathrm{D}$ than the Gc2 variant [7], potentially leading to more efficient delivery of $25(\mathrm{OH}) \mathrm{D}$ to the target tissues, while the Gc2 variant is associated with decreased circulating concentrations of $25(\mathrm{OH}) \mathrm{D}$, $1,25(\mathrm{OH})_{2} \mathrm{D}$ and DBP $[8,9]$. We therefore reasoned that possession of the Gc2 variant of DBP might associate with susceptibility to TB, and conducted
AFFILIATIONS

Author affiliation details can be found in the Acknowledgements section of this manuscript.

${ }^{*}$ Both authors contributed equally to this work.

\section{CORRESPONDENCE}

A.R. Martineau

Centre for Health Sciences

Queen Mary's School of Medicine and Dentistry

Barts and The London

London E1 2AT

UK

E-mail: a.martineau@qmul.ac.uk

Received:

June 022009

Accepted after revision:

Sept 082009

First published online:

Sept 242009 
case-control studies in three different settings to test this hypothesis. We also conducted functional studies to determine whether antigen-stimulated release of interferon (IFN)- $\gamma$ from whole blood of healthy TB contacts varied according to Gc genotype.

\section{METHODS}

\section{Populations studied}

Case-control study participants were recruited at three sites (table 1). 1) 123 adult TB patients and 140 healthy adult TB contacts, all of Gujarati Asian ethnic origin, were recruited at Northwick Park Hospital, London, UK, from 1993 to 2004. 2) 281 children with TB (210 Xhosa and 71 of Cape Coloured ethnic origin) and 182 healthy child TB contacts (163 Xhosa and 19 Cape Coloured ethnic origin) were recruited at the Red Cross Children's Hospital, Cape Town, South Africa, from 2000 to 2003. 3) 130 adult TB patients (55 White, 31 Black, and 44 of mixed ethnic origin) and 78 healthy adult controls (49 White, 11 Black, and 18 of mixed ethnic origin) were recruited in Instituto de Pesquisa Clínica Evandro Chagas (IPEC) at Fiocruz and in Municipal Health Centres, Rio de Janeiro, Brazil, from 2004 to 2007.

Diagnosis of TB was established on the basis of smear positive for acid-fast bacilli and/or culture positive for Mycobacterium tuberculosis in all adult cases and in 33\% of paediatric cases; for the remaining paediatric cases, diagnosis was based on World Health Organization (WHO) criteria for diagnosis of TB in children [10], with $42 \%$ classified as having probable TB and $25 \%$ classified as having possible TB. Patients with known HIV infection and those who were taking immunosuppressant drugs were excluded. Adult TB contacts were recruited at participating TB clinics and health centres in London and Rio de Janeiro on the basis of: a history of household contact with a TB patient; absence of symptoms of active TB; and being genetically unrelated to any patient recruited as a TB case in the study. Child TB contacts were recruited by locating children living three houses adjacent to a household in which a childhood TB case was identified. Where possible, it was ensured that child controls were unrelated to child TB cases. All adult participants gave informed consent for inclusion, as did parents of child participants. Permission to conduct the case-control study was obtained from research ethics committees in the UK (Harrow REC ref. 1646), South Africa (University of Cape Town REC ref. 013/2000) and Brazil (IPEC REC ref. 0008.0.009.000-04 and Rio de Janeiro Municipal Health Centre REC ref. S/CRH/DRH/DIC3).

\begin{tabular}{lccc}
\hline TABLE 1 & Study populations & & \\
Location & Ethnic group & Cases & Controls \\
\hline \multirow{2}{*}{ London, UK } & Gujarati Asian & 123 adults & 140 adults \\
Cape Town, South Africa & Xhosa & 210 children & 163 children \\
& Cape Coloured & 71 children & 19 children \\
Rio de Janeiro, Brazil & White & 55 adults & 49 adults \\
& Mixed ethnic origin & 44 adults & 18 adults \\
& Black & 31 adults & 11 adults \\
\hline
\end{tabular}

Functional studies were also conducted in a group of 36 healthy TB contacts recruited to a clinical trial of vitamin D supplementation at Northwick Park Hospital $(n=28)$ and Newham Chest Clinic $(n=8)$, London, UK, from 2002 to 2005. Characteristics of the whole study population have been reported elsewhere [11]. The subgroup of 36 participants, whose results are presented here, was selected on the basis of selfassigned Gujarati Asian ethnicity and the availability of a result from whole blood IFN- $\gamma$ release assay (IGRA) performed prior to randomisation. The study was approved by the research ethics committees of North East London and Harrow (REC refs. $\mathrm{P} / 02 / 146$ and EC 2759, respectively) with written, informed consent to take part in the study obtained from all participants.

\section{Genotyping}

Genomic DNA was extracted from peripheral blood samples using the DNA Midi Kit (Qiagen, Lewes, UK). A 483-bp fragment of exon 11 of the Gc gene was amplified by PCR. Reaction mix included: $2 \mu \mathrm{L}$ DNA at $50 \mu \mathrm{L} \cdot \mathrm{mL}^{-1} ; 11.1 \mu \mathrm{L} \mathrm{H}_{2} \mathrm{O}$; $2 \mu \mathrm{L} 10 \times$ PCR buffer; $0.4 \mu \mathrm{L} 25 \mathrm{mM} \mathrm{MgCl}{ }_{2} ; 0.4 \mu \mathrm{L} 10 \mathrm{mM}$ deoxynucleotide triphosphates; $0.1 \mu \mathrm{L}$ HotStar Taq polymerase (Qiagen); and $2 \mu \mathrm{L}$ of $20 \mu \mathrm{M}$ primers. Primer sequences were 5'AAATAATGAGCAAATGAAAGAAGAC-3' (forward) and 5'CAATAACAGCAAAGAAATGAGTAGA-3' (reverse). Cycling conditions were $95^{\circ} \mathrm{C}$ for $15 \mathrm{~min}$, followed by 35 cycles at $94^{\circ} \mathrm{C}$ for $45 \mathrm{~s}, 51^{\circ} \mathrm{C}$ for $45 \mathrm{~s}, 72^{\circ} \mathrm{C}$ for $45 \mathrm{~s}$, and then a final $7 \mathrm{~min}$ at $72^{\circ} \mathrm{C}$. PCR products were digested separately with restriction enzymes HaeIII (for $4 \mathrm{~h}$ at $37^{\circ} \mathrm{C}$ ) and StyI (overnight at $37^{\circ} \mathrm{C}$ ) (New England Biolabs, Mississauga, OT, USA). Digestion with HaeIII produces 297- and 186-bp fragments in the presence of the $\mathrm{h}$ allele, and digestion with StyI produces 305- and 178-bp fragments in the presence of the s allele. Digested products were visualised on $2 \%$ agarose gels stained with ethidium bromide. The presence of restriction sites was assigned by the lower case (h for HaeIII, s for StyI), and absence was assigned by the upper case (H for HaeIII and S for StyI). Gc genotype was assigned as seen in table 2.

\section{Determination of 25(OH)D concentrations}

Serum 25(OH)D concentrations of Gujarati Asian participants recruited in London were determined by radio-immunoassay (DiaSorin, Stillwater, MN, USA) in a clinical biochemistry laboratory that participates in the international vitamin D external quality assessment programme (www.deqas.org). For participants with active $\mathrm{TB}$, serum $25(\mathrm{OH}) \mathrm{D}$ concentrations were determined at diagnosis. Vitamin $\mathrm{D}$ deficiency was defined as serum $25(\mathrm{OH}) \mathrm{D}<20 \mathrm{nmol} \cdot \mathrm{L}^{-1}$ [12].

\section{IGRA}

The IGRA used in this study has been described elsewhere [13]. Triplicate samples of venous blood diluted 1:10 with RPMI-1640 (Life Technologies, Paisley, UK) were cultured with $1,000 \mathrm{U} \cdot \mathrm{mL}^{-1} \mathrm{PPD}$ (Statens Serum Institute, Copenhagen, Denmark), $2.5 \mu \mathrm{g} \cdot \mathrm{mL}^{-1}$ recombinant ESAT-6 or $5 \mu \mathrm{g} \cdot \mathrm{mL}^{-1}$ culture filtrate protein (CFP)-10 (Lionex, Braunschweig, Germany) at $37^{\circ} \mathrm{C}$ in $5 \% \mathrm{CO}_{2}$. Supernatants were aspirated at $96 \mathrm{~h}$ for determination of IFN- $\gamma$ concentration by ELISA.

\section{Statistical analysis}

Due to similar functional characteristics [7], Gc1F and Gc1S allele carriers were combined to produce a total of three 


\section{TABLE 2 Deduction of vitamin D binding protein (DBP) genotype from Haelll and Styl genotypes}

\begin{tabular}{|c|c|c|c|}
\hline HaellI/Styl genotype & Potential Haell//Styl haplotypes & Deduced HaellI/Styl haplotypes & Corresponding DBP genotype \\
\hline HH SS & $\mathrm{HS} / \mathrm{HS}$ & $\mathrm{HS} / \mathrm{HS}$ & Gc1F/Gc1F \\
\hline $\mathrm{HH}$ ss & $\mathrm{Hs} / \mathrm{Hs}$ & $\mathrm{Hs} / \mathrm{Hs}$ & Gc2/Gc2 \\
\hline Hh SS & $\mathrm{HS} / \mathrm{hS}$ & $\mathrm{HS} / \mathrm{hS}$ & Gc1F/Gc1S \\
\hline $\mathrm{Hh}$ Ss & $\mathrm{Hs} / \mathrm{hS}$ or $\mathrm{HS} / \mathrm{hs}^{\#}$ & $\mathrm{Hs} / \mathrm{hS}$ & Gc2/Gc1S \\
\hline
\end{tabular}

\#: frequency of the hs haplotype is extremely low due to linkage disequilibrium between loci; therefore subjects heterozygous at both loci were assumed to carry Hs/hS haplotypes, and subjects with potential haplotype hs were not assigned a DBP genotype.

genotypes: Gc1/1, Gc2/1 and Gc2/2. Contingency tables were analysed using Chi-squared tests, unless $>20 \%$ of cells in a table had an expected frequency of less than five, when Fisher's exact tests were employed. Linkage disequilibrium was evaluated by calculating predicted haplotype frequencies based on random assortment of HaeIII and StyI alleles, and comparing these with observed frequencies by a Chi-squared test; $\mathrm{D}^{\prime}$ was calculated using Lewontin's equation [14]. Mean ages were compared between groups using unpaired $\mathrm{t}$-tests and one-way ANOVA, and median serum $25(\mathrm{OH})$ D concentrations were compared between different groups using Kruskal-Wallis tests. Chi-squared tests were performed to test for associations between genotype and susceptibility to $T B$, and binary logistic regression analysis was conducted to adjust OR for age and sex. Data were analysed using SPSS (version 16.0; SPSS Inc. Chicago, IL, USA) and GraphPad Prism (version 4.03; GraphPad Software Inc., San Diego, CA, USA) software packages.

\section{RESULTS}

\section{Participant characteristics: case-control study}

The characteristics of the case-control study participants are presented in table 3. Gujarati Asian cases and controls did not differ with respect to age or sex distribution. Males were overrepresented in cases versus controls among participants recruited in Cape Town (Xhosa: 55.2 versus 41.1\% male, $\mathrm{p}=0.007$; Cape Coloured: 47.9 versus $21.1 \%$ male, $\mathrm{p}=0.04)$ and Rio de Janeiro (Black: 61.3 versus $27.3 \%$ male, $\mathrm{p}=0.01$; mixed ethnic origin: 63.6 versus $38.9 \%$ male, $p=0.02$ ). The mean age of cases was lower than that of controls among Xhosa participants in Cape Town (5.2 versus 6.1 yrs of age, $\mathrm{p}=0.002$ ) and higher than that of controls among White participants in Rio de Janeiro (38.7 versus 29.6 yrs, $\mathrm{p}<0.001$ ).

\section{DBP allele frequency varies between ethnic groups}

DBP allele frequency varied significantly between different ethnic groups ( $p<0.0001$; table 4$)$. Frequency of the Gc2 allele was highest among Gujarati Asian participants in London and white participants in Rio de Janeiro (35.9 and 33.2\%, respectively), and lowest among black participants in Rio de Janeiro and Xhosa participants in Cape Town (11.9 and 4.6\%, respectively). A similar ethnic distribution was observed for the Gc1S allele (47.9\% in Gujarati Asians in London, $41.8 \%$ in white participants in Rio de Janeiro, 19\% in black participants in
Rio de Janeiro, and 7.9\% in Xhosa participants in Cape Town). The opposite ethnic distribution was observed for the Gc1F allele, which was most common among Xhosa participants in Cape Town and black participants in Rio de Janeiro (87.5 and $69.0 \%$, respectively), and least common among white participants in Rio de Janeiro and Gujarati Asian participants in London (25.0 and $16.2 \%$ respectively). Intermediate frequencies of all three alleles were found among ethnically admixed participants recruited in Rio de Janeiro and Cape Town. Both loci were in Hardy-Weinberg equilibrium in all populations studied. The loci were in linkage disequilibrium in Gujarati Asian participants $\left(\mathrm{D}^{\prime}=0.52, \mathrm{p}<0.0001\right)$, white participants in Rio $\left(\mathrm{D}^{\prime}=0.36, \mathrm{p}<0.0001\right)$, and in ethnically admixed populations in Rio de Janeiro $\left(\mathrm{D}^{\prime}=0.15, \mathrm{p}<0.0001\right)$ and Cape Town $\left(\mathrm{D}^{\prime}=0.06\right.$, $\mathrm{p}=0.0002)$, but not in Xhosa participants in Cape Town $(\mathrm{p}=0.08)$ or black participants in Rio de Janeiro $(\mathrm{p}=0.10)$.

\section{TABLE 3 Characteristics of tuberculosis cases and controls}

\begin{tabular}{lccc} 
Ethnic group characteristics & Cases & Controls & p-value \\
\hline $\begin{array}{l}\text { Gujarati Asian } \\
\quad \text { Age yrs }\end{array}$ & $43.8 \pm 16.2$ & $41.9 \pm 13.3$ & 0.3 \\
$\quad \begin{array}{l}\text { Males } \\
\text { Xhosa }\end{array}$ & $47(38.2)$ & $67(47.9)$ & 0.12 \\
$\quad$ Age yrs & $5.2 \pm 3.9$ & $6.1 \pm 3.6$ & 0.002 \\
$\quad$ Males & $116(55.2)$ & $67(41.1)$ & 0.007 \\
Cape Coloured & & & \\
$\quad$ Age yrs & $4.4 \pm 3.9$ & $5.5 \pm 4.1$ & 0.16 \\
$\quad$ Males & $34(47.9)$ & $4(21.1)$ & 0.04 \\
White & & & \\
$\quad$ Age yrs & $38.7 \pm 13.8$ & $29.6 \pm 10.3$ & $<0.001$ \\
$\quad$ Males & $37(67.3)$ & $16(32.7)$ & 0.2 \\
Mixed ethnic origin & & & \\
$\quad$ Age yrs & $36.6 \pm 11.9$ & $34.9 \pm 13.6$ & 0.63 \\
$\quad$ Males & $28(63.6)$ & $7(38.9)$ & 0.02 \\
Black & & & \\
$\quad$ Age yrs & $38.0 \pm 13.7$ & $33.6 \pm 14.8$ & 0.37 \\
$\quad$ Males & $19(61.3)$ & $3(27.3)$ & 0.01 \\
\hline
\end{tabular}

Data are presented as mean \pm SD or $n(\%)$, unless otherwise stated. 


\begin{tabular}{|c|c|c|c|}
\hline TABLE 4 & $\begin{array}{l}\text { y of vitam } \\
\text { cording to }\end{array}$ & $\begin{array}{l}\text { binding pr } \\
\text { hic group }\end{array}$ & (DBP) \\
\hline \multirow[t]{2}{*}{ Ethnic group } & \multicolumn{3}{|c|}{ DBP allele } \\
\hline & Gc2 & Gc1F & Gc1S \\
\hline Gujarati Asian & 189 (35.9) & 85 (16.2) & 252 (47.9) \\
\hline Xhosa & $34(4.6)$ & $653(87.5)$ & $59(7.9)$ \\
\hline Cape Coloured & 24 (13.3) & $108(60.0)$ & $48(26.7)$ \\
\hline White & 69 (33.2) & $52(25.0)$ & $87(41.8)$ \\
\hline Mixed ethnic origin\# & 26 (21.3) & $52(42.6)$ & 45 (36.3) \\
\hline Black & $10(11.9)$ & $58(69.0)$ & $16(19.0)$ \\
\hline
\end{tabular}

\section{Carriage of the Gc2 allele associates with susceptibility to active TB in Gujarati Asians}

Given that the allele frequency varied by ethnic group, casecontrol analysis of DBP variant frequency was stratified by ethnic group. Among Gujarati Asian participants, the Gc genotype was associated with active TB $(p=0.04$; table 5$)$. The unadjusted OR for Gc2/2 compared with Gc1/1 was 2.81 (95\% CI 1.19-6.66; $\mathrm{p}=0.009$ ), while the unadjusted OR for Gc2/1 compared with Gc1/1 was $1.69(0.96-2.96 ; \mathrm{p}=0.052)$. The unadjusted OR for genotypes Gc2/1 and Gc2/2 combined versus $\mathrm{Gc} 1 / 1$ was 1.89 (1.11-3.22; $\mathrm{p}=0.012)$. These associations were unaltered by adjustment for age and sex (adjusted OR for Gc2/2 versus Gc1/1 was 2.83 (1.27-6.31), $\mathrm{p}=0.01$; adjusted OR for $\mathrm{Gc} 2 / 1$ versus $\mathrm{Gc} 1 / 1$ was 1.73 (1.01-2.96), $\mathrm{p}=0.045$; adjusted OR for Gc2/1 and Gc2/2 combined versus Gc1/1 was 1.94 (1.173.23), $\mathrm{p}=0.01$ ). No statistically significant variation in the frequency of DBP genotype was observed between cases and controls among any of the populations studied in Cape Town or Rio de Janeiro, either before or after adjustment for age and sex.

\section{Vitamin $D$ status does not vary with DBP variant in Gujarati Asians}

In a previous study, we showed that vitamin D deficiency was associated with susceptibility to TB in Gujarati Asians [15]. Since then, other studies have reported that serum $25(\mathrm{OH}) \mathrm{D}$ concentrations vary with Gc genotype, the lowest being in carriers of the Gc2 allele $[8,9]$. We were interested to determine whether serum $25(\mathrm{OH}) \mathrm{D}$ concentrations varied according to Gc genotype in Gujarati Asians. As serum samples were not collected prospectively for this purpose, we conducted a retrospective search for results of routinely performed assays of serum 25(OH)D concentration for all Gujarati Asian participants. Results were available for 84 out of the 123 cases and 55 out of the 140 controls. Vitamin D deficiency (serum $25(\mathrm{OH}) \mathrm{D}<20 \mathrm{nmol} \cdot \mathrm{L}^{-1}$ ) was more common among TB cases versus controls (affecting 60 out of 84 versus 31 out of 55) but this difference did not attain statistical significance $(p=0.07)$. No significant differences in median serum $25(\mathrm{OH}) \mathrm{D}$ concentration or prevalence of vitamin $\mathrm{D}$ deficiency were observed between individuals with different genotypes (median serum 25(OH)D: 17.0 versus 12.0 versus $10.0 \mathrm{nmol} \cdot \mathrm{L}^{-1}$ for Gc1/1, Gc1/2 and Gc2/2 genotypes, respectively, $\mathrm{p}=0.28$; prevalence of vitamin $\mathrm{D}$

\begin{tabular}{|c|c|c|c|c|c|}
\hline \multirow{3}{*}{$\begin{array}{l}\text { TABLE } 5 \\
\text { Ethnic group }\end{array}$} & \multicolumn{5}{|c|}{$\begin{array}{l}\text { Frequency of vitamin D binding protein (DBP) } \\
\text { genotypes: tuberculosis cases versus controls }\end{array}$} \\
\hline & \multirow[t]{2}{*}{ Subjects n } & \multicolumn{3}{|c|}{ DBP genotype } & \multirow[t]{2}{*}{ p-value } \\
\hline & & Gc2/2 & Gc2/1 & Gc1/1 & \\
\hline \multicolumn{6}{|l|}{ Gujarati Asian } \\
\hline Cases & 123 & $22(17.9)$ & $60(48.7)$ & 41 (33.3) & 0.04 \\
\hline Controls & 140 & $13(9.3)$ & $59(42.1)$ & $68(48.5)$ & \\
\hline \multicolumn{6}{|l|}{ Xhosa } \\
\hline Cases & 210 & $0(0)$ & $20(9.5)$ & $190(90.5)$ & 0.86 \\
\hline Controls & 163 & $0(0)$ & $14(8.6)$ & $149(91.4)$ & \\
\hline \multicolumn{6}{|l|}{ Cape Coloured } \\
\hline Cases & 71 & $3(4.2)$ & $14(19.7)$ & $54(76.1)$ & $>0.99$ \\
\hline Controls & 19 & $0(0)$ & $4(21.1)$ & 15 (78.9) & \\
\hline \multicolumn{6}{|l|}{ White } \\
\hline Cases & 55 & $8(14.5)$ & $20(36.4)$ & $27(49.1)$ & 0.56 \\
\hline Controls & 49 & $5(10.2)$ & $23(46.9)$ & 21 (42.9) & \\
\hline \multicolumn{6}{|l|}{$\begin{array}{l}\text { Mixed ethnic } \\
\text { origin }\end{array}$} \\
\hline Cases & $44^{\#}$ & $2(4.5)$ & $12(27.3)$ & 29 (65.9) & 0.64 \\
\hline Controls & 18 & $2(11.1)$ & $6(33.3)$ & $10(55.6)$ & \\
\hline \multicolumn{6}{|l|}{ Black } \\
\hline Cases & 31 & $1(3.2)$ & $5(16.1)$ & 25 (80.6) & 0.75 \\
\hline Controls & 11 & $0(0)$ & $3(27.3)$ & $8(72.7)$ & \\
\hline
\end{tabular}

Data are presented $n(\%)$, unless otherwise stated. Gc: group-specific component. *: DBP genotype not assigned for one case (Haell genotype hh, Styl genotype Ss).

deficiency: 35 out of 58 versus 43 out of 63 versus 13 out of 18 for Gc1/1, Gc1/2 and Gc2/2 genotypes, respectively, $\mathrm{p}=0.53$ ).

\section{The association between Gc genotype and susceptibility to TB in Gujarati Asian participants varies according to vitamin $D$ status}

Next, we investigated whether associations between Gc genotype and susceptibility to TB in Gujarati Asians varied according to vitamin $\mathrm{D}$ status by performing separate contingency analyses for vitamin D-deficient participants and nondeficient participants (table 6). Among vitamin D-deficient Gujarati Asians, we found that the Gc genotype was strongly associated with susceptibility to TB, with Gc2/2 present in 13 out of 60 vitamin D-deficient cases versus zero out of 31 vitamin D-deficient controls $(p=0.01)$. In contrast, no association between Gc genotype and susceptibility to TB was seen among Gujarati Asians with serum 25(OH)D $\geqslant 20 \mathrm{nmol} \cdot \mathrm{L}^{-1}(\mathrm{p}=0.36)$. Statistical analysis to determine whether Gc genotype and vitamin $\mathrm{D}$ status interact to influence susceptibility to TB was indeterminate, as the zero value for vitamin D-deficient controls with Gc2/2 genotype in the contingency table (table 6) resulted in an undefined OR.

\section{Carriage of the Gc2 allele is associated with increased IFN- $\gamma$ release from PPD-stimulated whole blood of Gujarati Asian TB contacts}

Finally, we investigated whether IFN- $\gamma$ responses to mycobacterial antigens varied according to Gc genotype in a group 


\begin{tabular}{|c|c|c|c|c|c|}
\hline \multirow{3}{*}{$\begin{array}{l}\text { TABLE } 6 \\
\text { Serum } \\
\text { 25(OH)D }\end{array}$} & \multicolumn{5}{|c|}{$\begin{array}{l}\text { Frequency of vitamin D binding protein (DBP) } \\
\text { genotypes in Gujarati Asian TB cases versus } \\
\text { controls, stratified by vitamin D status }\end{array}$} \\
\hline & \multirow[t]{2}{*}{ Subjects $n$} & \multicolumn{3}{|c|}{ DBP genotype } & \multirow[t]{2}{*}{$\mathrm{p}$-value } \\
\hline & & Gc2/2 & $\mathrm{Gc2} / 1$ & $\mathrm{Gc} 1 / 1$ & \\
\hline \multicolumn{6}{|l|}{$<20 \mathrm{nmol} \cdot \mathrm{L}^{-1}$} \\
\hline Cases & 60 & $13(21.7)$ & $26(43.3)$ & $21(35.0)$ & 0.01 \\
\hline Controls & 31 & $0(0)$ & $17(54.8)$ & $14(45.2)$ & \\
\hline \multicolumn{6}{|l|}{$\geqslant 20 \mathrm{nmol} \cdot \mathrm{L}^{-1}$} \\
\hline Cases & 24 & $3(12.5)$ & $12(50)$ & $9(37.5)$ & 0.36 \\
\hline Controls & 24 & $2(8.3)$ & 8 (33.3) & $14(58.3)$ & \\
\hline
\end{tabular}

Data are presented as $n(\%)$, unless otherwise indicated. 25(OH)D: 25hydroxyvitamin D; Gc: group-specific component.

of 36 Gujarati Asian TB contacts whose characteristics are presented in table 7. No significant differences in sex ratio, bacille Calmette-Guerin (BCG) status, tuberculin skin test reactivity, site of exposure or vitamin $\mathrm{D}$ status were observed between participants of different Gc genotype, although a statistically significant difference in mean age was observed between participants of different genotype (55.3 versus 41.3 versus 34.9 yrs for genotypes Gc2/2, Gc2/1 and Gc1/1, respectively, $\mathrm{p}=0.03)$. Median PPD-stimulated IFN- $\gamma$ concentration was higher among TB contacts of $\mathrm{Gc} 2 / 2$ and $\mathrm{Gc} 2 / 1$ genotype versus those of Gc1/1 genotype (790.8 versus 663.5 versus $60.5 \mathrm{pg} \cdot \mathrm{mL}^{-1}$ respectively, $\mathrm{p}=0.02$; fig. 1 ); no difference in ESAT-6 or CFP-10-stimulated IFN- $\gamma$ concentration was observed between TB contacts of different genotype (table 7).

\section{DISCUSSION}

We have demonstrated an association between the Gc genotype of DBP and susceptibility to TB in Gujarati Asians living in London. Stratification of this analysis by vitamin D status revealed that this association was restricted to participants with profound vitamin D deficiency.

No association between carriage of the Gc2 allele and susceptibility to TB was observed among populations studied in Rio de Janeiro and Cape Town. Gc2 allele frequency in these populations was lower than in Gujarati Asians, and absolute numbers of Gc2 carriers were therefore small (table 4); our study may have been underpowered to detect an association in these populations. An alternative explanation for the lack of association seen in Rio de Janeiro and Cape Town is that populations in Rio de Janeiro (latitude $22^{\circ} \mathrm{S}$ ) and Cape Town (latitude $33^{\circ} \mathrm{S}$ ) are likely to have significantly more exposure to UVB than those living in London (latitude $51^{\circ} \mathrm{N}$ ). Profound vitamin D deficiency is therefore likely to be much less common in these settings. If the association between Gc2 allele and susceptibility to TB is restricted to individuals with profound vitamin D deficiency, as we postulate, then low prevalence of vitamin $\mathrm{D}$ deficiency in Rio de Janeiro and Cape Town may explain non-replication of the association in these settings. This explanation may also account for the lack of association between Gc genotype and susceptibility to TB in other populations previously studied in Kuwait [16] and India [17].

Individuals carrying the Gc2 allele have previously been reported to have lower circulating concentrations of both DBP and $25(\mathrm{OH}) \mathrm{D}[8,9,18]$, phenomena that have been attributed to the fact that the gene product of the Gc2 allele is metabolised faster than that of Gc1 alleles [19]. Vitamin D-deficient carriers of the Gc2 allele may therefore have particularly low circulating concentrations of 25(OH)D-DBP complex. Receptor-mediated endocytosis of $25(\mathrm{OH}) \mathrm{D}-\mathrm{DBP}$ complex has previously been shown to be essential for induction of vitamin D-mediated biological activity in both renal and mammary cells [20, 21]. If $25(\mathrm{OH}) \mathrm{D}-\mathrm{DBP}$ complex is similarly required for initiation of vitamin D-inducible antimycobacterial responses, then reduced circulating concentrations of this complex in vitamin D-deficient

TABLE 7 Characteristics of functional study participants by group-specific component (Gc) genotype

\begin{tabular}{|c|c|c|c|c|}
\hline & Gc2/2 & Gc2/1 & Gc1/1 & $p$-value \\
\hline Subjects $\mathrm{n}$ & 7 & 20 & 9 & \\
\hline Male sex & $3(42.9)$ & $11(55.0)$ & $3(33.3)$ & 0.54 \\
\hline BCG scar present & $6(85.7)$ & $15(75.0)$ & $8(88.9)$ & 0.63 \\
\hline UK born & $3(42.9)$ & $6(30.0)$ & $3(33.3)$ & 0.35 \\
\hline $25(\mathrm{OH}) \mathrm{D}<20 \mathrm{nmol} \cdot \mathrm{L}^{-1}$ & $3(42.9)$ & $12(60.0)$ & $5(55.6)$ & 0.73 \\
\hline Serum $25(\mathrm{OH}) \mathrm{D} \mathrm{nmol} \cdot \mathrm{L}^{-1}$ & $25.0(13.2-43.0)$ & $18.4(9.5-27.9)$ & $17.5(7.1-37.0)$ & 0.63 \\
\hline PPD-stimulated IFN- $\gamma \mathrm{pg} \cdot \mathrm{mL}^{-1}$ & $790.8(118.6-1311.0)$ & $663.5(208.3-2162.0)$ & $60.5(22.7-170.4)$ & 0.02 \\
\hline ESAT-6-stimulated IFN- $\gamma \mathrm{pg} \cdot \mathrm{mL}^{-1}$ & $16.6(0.0-324.9)$ & $53.2(20.7-233.7)$ & $52.9(0.0-154.3)$ & 0.60 \\
\hline CFP-10-stimulated IFN- $\gamma \mathrm{pg} \cdot \mathrm{mL}^{-1}$ & $0.0(0.0-23.6)$ & $53.1(0.0-263.1)$ & $0.0(0.0-62.8)$ & 0.29 \\
\hline
\end{tabular}

Data are presented mean $\pm \mathrm{SD}, \mathrm{n}(\%)$ and median (interquartile range), unless otherwise stated. BCG: bacille Calmette-Guerin; 25(OH)D: 25-hydroxyvitamin D; IFN- $\gamma$ : interferon- $\gamma$; CFP-10: culture filtrate protein 10 . ${ }^{\#}$ : reactive tuberculin status defined as Heaf grade 3 or 4 , or Heaf grade 2 in the absence of a BCG scar; negative tuberculin status defined as Heaf grade 0 or 1 , or Heaf grade 2 in the presence of a BCG scar. Tuberculin skin test results were available for five out of seven participants with Gc2/2, 13 out of 20 with Gc2/1 and five out of nine with Gc1/1. 


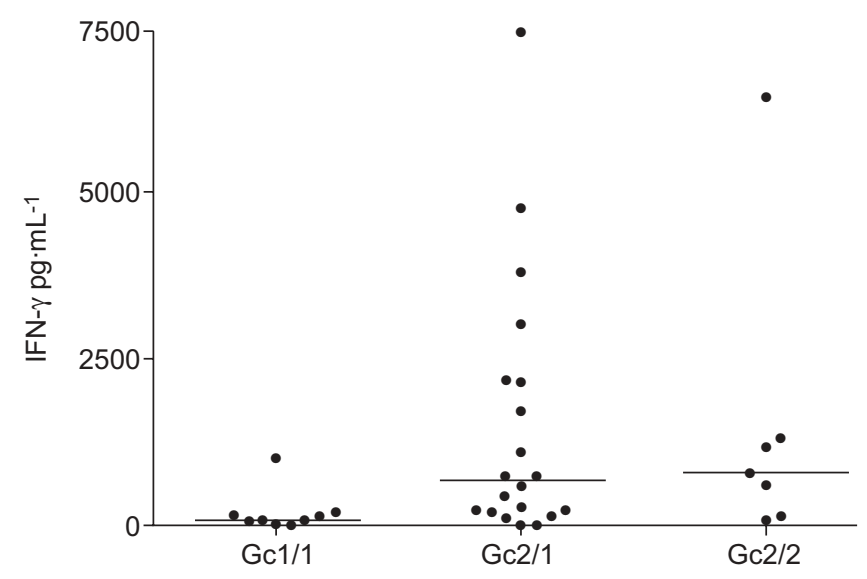

FIGURE 1. Purified protein derivative of tuberculin-stimulated interferon (IFN)- $\gamma$ release in functional study participants by group-specific component (Gc) genotype.

carriers of the Gc2 allele could explain the association that we report. Further studies are required to establish whether circulating concentrations of 25(OH)D-DBP complex vary according to Gc allele, and to investigate whether receptormediated endocytosis of 25(OH)D-DBP complex is essential for induction of vitamin D-inducible antimycobacterial responses.

Our finding of a striking ethnic variation in Gc allele frequency is in keeping with published literature reporting that populations with deeply pigmented skin have higher frequencies of the Gc1F allele [22]. Reports that cutaneous penetration of UVB is decreased in individuals with pigmented skin [23] and that the Gc1 variants of DBP have greater affinity for $25(\mathrm{OH}) \mathrm{D}$ than the Gc2 variant [24] raise the possibility that Gc1 variants may carry a survival advantage in persons with pigmented skin due to their superior delivery of $25(\mathrm{OH}) \mathrm{D}$ to the target tissues. If this is the case, then the observation of increasing frequency of the Gc2 allele in Caucasian populations implies that possession of this allele confers a survival benefit in conditions where solar radiation is limited. Consistent with this hypothesis, possession of the Gc2 allele has been associated with decreased risk of several other pathologies, including breast cancer [9], chronic obstructive pulmonary disease [25] and fractures [26]. We also observed that alleles of the loci at codons 416 and 420 were in linkage disequilibrium in Gujarati Asian participants, white participants and ethnically admixed populations, but not in Xhosa or black participants. This phenomenon has been demonstrated for other coding single nucleotide polymorphisms in multiethnic populations, and may be attributed to a "bottleneck" experienced by Asian and European populations migrating from Africa around 800-1,600 generations ago [27].

Our functional study revealed that TB contacts carrying the Gc2 allele had significantly higher PPD-stimulated IFN- $\gamma$ responses than Gc1 homozygotes, who demonstrated low or undetectable IFN- $\gamma$ responses to PPD; all TB contacts had low or undetectable IFN- $\gamma$ responses to region of difference 1encoded antigens. ESAT-6 and CFP-10 are secreted early in infection, and reversion of IFN- $\gamma$ responses to these antigens with persistence of tuberculin reactivity has been previously reported in longitudinal studies of TB contacts, and may represent latent TB infection [28]. Our data may therefore indicate that Gc1 homozygotes are relatively resistant to acquisition of latent TB infection, and that Gc2 allele carriers are more susceptible.

Our study has some limitations. Gujarati Asian ethnicity was self-assigned, and although the community is genetically homogenous [15], the possibility of ethnic admixture cannot be excluded. Serum 25(OH)D concentrations were only available for $68 \%$ of Gujarati Asian cases versus 39\% of Gujarati Asian controls. This difference presumably arose because clinicians had a lower threshold for testing vitamin $\mathrm{D}$ status in TB cases than in TB contacts. Since the Gc2/2 genotype was less common among controls than cases, the absolute number of Gc2/2 controls with known vitamin D status was small $(n=2)$. However, the proportion of participants for whom $25(\mathrm{OH}) \mathrm{D}$ was available did not differ by Gc genotype, and the results of this analysis cannot therefore be attributed to selection bias. Larger studies with prospective evaluation of circulating concentrations of 25(OH)D should be performed in populations at risk of vitamin D deficiency to determine whether profound vitamin D deficiency and Gc2 genotype interact to increase susceptibility to TB.

\section{SUPPORT STATEMENT}

This work was supported by: the Scadding-Morriston Davies Joint Fellowship in Respiratory Medicine awarded to A.R. Martineau; a Beit Fellowship awarded to S.T. Anderson; the Wellcome Trust (refs 066321 and 072070); and the Fiocruz/Brazilian Ministry of Health. The funding bodies played no part in: the design or conduct of the study; the collection, management, analysis, and interpretation of the data; or the preparation, review, or approval of the manuscript. A.R. Martineau had full access to all of the data in the study and takes responsibility for the integrity of the data and the accuracy of the data analysis.

\section{STATEMENT OF INTEREST}

None declared.

\section{ACKNOWLEDGEMENTS}

The authors' affiliation details are as follows. A.R. Martineau: Wellcome Trust Centre for Research in Clinical Tropical Medicine, Division of Medicine, Imperial College London, London, UK; Centre for Health Sciences, Queen Mary's School of Medicine and Dentistry, Barts and The London, London, UK; Division of Mycobacterial Research, National Institute of Medical Research, Mill Hill, UK. A.C.C.S. Leandro, M.A. Rocha and M.G. Bonecini-Almeida: Laboratório de Imunologia e Imunogenética, Instituto de Pesquisa Clínica Evandro Chagas, FIOCRUZ, Rio de Janeiro, Brazil. S.T. Anderson, S.M. Newton and M. Levin: Academic Dept of Paediatrics, Division of Medicine, Imperial College London, London, UK. K.A. Wilkinson: Division of Mycobacterial Research, National Institute of Medical Research, Mill Hill, UK; Institute of Infectious Diseases and Molecular Medicine, Faculty of Health Sciences, University of Cape Town, Cape Town, South Africa. M.P. Nicol: Institute of Infectious Diseases and Molecular Medicine, Faculty of Health Sciences, University of Cape Town, Cape Town, South Africa; Division of Medical Microbiology, Faculty of Health Sciences, and National Health Laboratory Services, University of Cape Town, Cape Town, South Africa. S.M. Pienaar and B.S. Eley: Paediatric Infectious Diseases Unit, Red Cross Children's Hospital, School of Child and Adolescent Health, University of Cape Town, Cape Town, South Africa. K.H. Skolimowska: Institute of Infectious Diseases and Molecular Medicine, Faculty of Health Sciences, University of Cape Town, Cape Town, South Africa. V.C. Rolla: Laboratório Clínico em Tuberculose e Micobacterias, Instituto de Pesquisa Clínica Evandro Chagas, FIOCRUZ, Rio de Janeiro, Brazil. R.N. Davidson: Tuberculosis 
Clinic, North West London Hospitals NHS Trust, Northwick Park Hospital, Harrow, UK. S.A. Bremner and C.J. Griffiths: Centre for Health Sciences, Queen Mary's School of Medicine and Dentistry, Barts and The London, London, UK. R.J. Wilkinson: Wellcome Trust Centre for Research in Clinical Tropical Medicine, London, UK; Division of Mycobacterial Research, National Institute of Medical Research, Mill Hill, UK; Institute of Infectious Diseases and Molecular Medicine, Faculty of Health Sciences, University of Cape Town, Cape Town, South Africa.

The authors would like to thank: D. Shah (Dept of Infection and Tropical Medicine, Northwick Park Hospital, Harrow, UK) for her assistance in locating patient records for this study; S. Rainbow and colleagues at the Department of Clinical Biochemistry (Northwick Park Hospital) for performing 25(OH)D assays; and R. Walton and B. Boucher of Barts and The London Medical School (London, UK) for helpful discussions and review of the manuscript.

\section{REFERENCES}

1 Nnoaham KE, Clarke A. Low serum vitamin D levels and tuberculosis: a systematic review and meta-analysis. Int $J$ Epidemiol 2008; 37: 113-119.

2 Martineau AR, Wilkinson RJ, Wilkinson KA, et al. A single dose of vitamin D enhances immunity to mycobacteria. Am J Respir Crit Care Med 2007; 176: 208-213.

3 Liu PT, Stenger S, Li H, et al. Toll-like receptor triggering of a vitamin D-mediated human antimicrobial response. Science 2006; 311: 1770-1773.

4 Martineau AR, Wilkinson KA, Newton SM, et al. IFN- $\gamma$ - and TNFindependent vitamin D-inducible human suppression of mycobacteria: the role of cathelicidin LL-37. J Immunol 2007; 178: 7190-7198.

5 Coussens A, Timms PM, Boucher BJ, et al. 1alpha,25-dihydroxyvitamin D inhibits matrix metalloproteinases induced by Mycobacterium tuberculosis infection. Immunology 2009; 127: 539-548.

6 Cleve $\mathrm{H}$, Constans J. The mutants of the vitamin-D-binding protein: more than 120 variants of the GC/DBP system. Vox Sang 1988; 54: 215-225.

7 Arnaud J, Constans J. Affinity differences for vitamin D metabolites associated with the genetic isoforms of the human serum carrier protein (DBP). Hum Genet 1993; 92: 183-188.

8 Lauridsen AL, Vestergaard P, Hermann AP, et al. Plasma concentrations of 25-hydroxy-vitamin D and 1,25-dihydroxyvitamin D are related to the phenotype of Gc (vitamin D-binding protein): a cross-sectional study on 595 early postmenopausal women. Calcif Tissue Int 2005; 77: 15-22.

9 Abbas S, Linseisen J, Slanger T, et al. The Gc2 allele of the vitamin $\mathrm{D}$ binding protein is associated with a decreased postmenopausal breast cancer risk, independent of the vitamin D status. Cancer Epidemiol Biomarkers Prev 2008; 17: 1339-1343.

10 WHO. Provisional guidelines for the diagnosis and classification of the EPI target diseases for primary health care, surveillance and special studies. Geneva, WHO, 1983.
11 Martineau AR, Newton SM, Wilkinson KA, et al. Neutrophilmediated innate immune resistance to mycobacteria. J Clin Invest 2007; 117: 1988-1994.

12 Compston JE. Vitamin D deficiency: time for action. Evidence supports routine supplementation for elderly people and others at risk. BMJ 1998; 317: 1466-1467.

13 Scholvinck E, Wilkinson KA, Whelan AO, et al. Gamma interferonbased immunodiagnosis of tuberculosis: comparison between wholeblood and immunospot methods. J Clin Microbiol 2004; 42: 829-831.

14 Lewontin RC. The interaction of selection and linkage. I. General considerations: heterotic models. Genetics 1964; 49: 49-67.

15 Wilkinson RJ, Llewelyn M, Toossi Z, et al. Influence of vitamin D deficiency and vitamin $\mathrm{D}$ receptor polymorphisms on tuberculosis among Gujarati Asians in west London: a case-control study. Lancet 2000; 355: 618-621.

16 Bahr GM, Eales LJ, Nye KE, et al. An association between Gc (vitamin D-binding protein) alleles and susceptibility to rheumatic fever. Immunology 1989; 67: 126-128.

17 Papiha SS, Agarwal SS, White I. Association between phosphoglucomutase (PGM1) and group-specific component (Gc) subtypes and tuberculosis. J Med Genet 1983; 20: 220-222.

18 Lauridsen AL, Vestergaard P, Nexo E. Mean serum concentration of vitamin D-binding protein (Gc globulin) is related to the Gc phenotype in women. Clin Chem 2001; 47: 753-756.

19 Kawakami M, Blum CB, Ramakrishnan R, et al. Turnover of the plasma binding protein for vitamin $\mathrm{D}$ and its metabolites in normal human subjects. J Clin Endocrinol Metab 1981; 53: 1110-1116.

20 Nykjaer A, Dragun D, Walther D, et al. An endocytic pathway essential for renal uptake and activation of the steroid $25-(\mathrm{OH})$ vitamin D3. Cell 1999; 96: 507-515.

21 Rowling MJ, Kemmis CM, Taffany DA, et al. Megalin-mediated endocytosis of vitamin D binding protein correlates with 25hydroxycholecalciferol actions in human mammary cells. J Nutr 2006; 136: 2754-2759.

22 Kamboh MI, Ferrell RE. Ethnic variation in vitamin D-binding protein (GC): a review of isoelectric focusing studies in human populations. Hum Genet 1986; 72: 281-293.

23 Clemens TL, Adams JS, Henderson SL, et al. Increased skin pigment reduces the capacity of skin to synthesise vitamin D3. Lancet 1982; 1: 74-76.

24 Constans J, Viau M, Bouissou C. Affinity differences for the 25$\mathrm{OH}-\mathrm{D} 3$ associated with the genetic heterogeneity of the vitamin Dbinding protein. FEBS Lett 1980; 111: 107-111.

25 Horne SL, Cockcroft DW, Dosman JA. Possible protective effect against chronic obstructive airways disease by the GC2 allele. Hum Hered 1990; 40: 173-176.

26 Lauridsen $\mathrm{AL}$, Vestergaard $\mathrm{P}$, Hermann $\mathrm{AP}$, et al. Female premenopausal fracture risk is associated with gc phenotype. J Bone Miner Res 2004; 19: 875-881.

27 Reich DE, Cargill M, Bolk S, et al. Linkage disequilibrium in the human genome. Nature 2001; 411: 199-204.

28 Hill PC, Brookes RH, Fox A, et al. Longitudinal assessment of an ELISPOT test for Mycobacterium tuberculosis infection. PLoS Med 2007; 4: e192. 